\title{
EVALUATION OF A UNIFIED FOOTBALL PROGRAM BY SPECIAL OLYMPICS ATHLETES, PARTNERS, PARENTS, AND COACHES
}

\author{
Funda Baran \\ Ece Top \\ Abdurahman Aktop \\ Dilara Özer \\ Sibel Nalbant \\ School of the Physical Education and Sport, Akdeniz University, Antalya, Turkey
}

\begin{abstract}
The purpose of the study was to compare the perceptions of athletes, partners, parents, and coaches regarding their commitment to the concept of Unified Sports, and their overall satisfaction with the 8 weeks Unified Football Program at the beginning and the end of the program. Participants were 46 boys with and without Intellectual Disabilities (ID) ( 23 with ID, mean age $=14.5 \pm 1.19$ years, 23 without ID, mean age $=14.1 \pm 0.89$ years $)$. The Unified Sport Questionnaire forms were administered to athletes, partners, coaches, and parents as a pretest in the second week of the training and a post test just after the tournaments. There were significant decrease in after program responses of partners in enjoyment of training ( $\mathrm{p}<.05, \mathrm{McNemar}$ 's test) and perception of the level of getting along with the other school friends ( $\mathrm{p}<.05, \mathrm{McNemar}$ 's test). In athletes, there was a significant increase only in the recommendation of Unified Sports to a friend ( $p<.05$,McNemar's test). Athletes' and partners' parents perceived improvements in abilities, behaviors and relations of their children. All of the coaches believed in the necessity of rule modification during the program. According to the results of this study, Unified Sports would enable to integrate children with intellectual disability into society and increase social awareness of their peers without disabilities.
\end{abstract}

KEYWORDS: Special Olympics, Unified Sports Program, intellectual disabilities, football.

\section{INTRODUCTION}

Intellectual disability (ID) is a disability characterized by significant limitations both in intellectual functioning and in adaptive behavior, which covers many everyday social and practical skills. This disability originates before the age of 18. Generally, an IQ test score of around 70 or as high as 75 indicates a limitation in intellectual functioning (AAIDD, 2009). According to World Health Organization approximately 3 percent of the world's population has an intellectual disability. That translates into 190 million people in the world making it the largest disability population (Roswal, 2007).

Integrating individuals with (ID) into community life has been a central goal of the disability movement for more than 30 years (Mahon, Mactavish, Bockstael, O'Dell, \& Siegenthaler, 2000). Integration, although defined in various ways, is commonly thought of as a process that brings people with and without disabilities together in shared physical settings where meaningful social interactions can be fostered and maintained (Hutchison \& McGill, 1992). Fundamental to this idea is that being part of the community positively influences the life quality of individuals with ID (Wehmeyer \& Schwartz, 1998).

Special Olympics (SO) has been a worldwide leader in providing year-round sport training and competition opportunities to athletes with ID. The movement began in 1962 when Eunice Kennedy Shriver started a day camp at her home for people with ID. In 1968, the First International Special Olympics Games were held. Over the past 37 years, Special Olympics has grown to serve 2 million athletes in over 150 countries, through 26 summers and winter games (Siperstein, Harada, Parker, Hardman, \& McGuire, 2008). 
Since its inception, Special Olympics has continually responded to changes in societal policies and attitudes toward individuals with ID. One such change has been the "inclusion movement" wherein individuals with ID participate in general education classroom and schools, integrated workplaces, and their local communities (Siperstein \& Hardman, 2001). The Unified Sports Program, developed by Special Olympics, is a new initiative, designed to help transition of athletes with ID to mainstream community sports. Unified Sports combines in approximately equal numbers of Special Olympics athletes and athletes without ID, of similar age and ability, on sport teams for training and competition. Unified Sports focuses on athletes with higher functional levels who are capable of playing in community based programs and especially those who can benefit from social interaction with their peers. Unified Sports members with ID are referred to as "athletes" and teammates without disabilities as "partners" (Roswal, 2007). Unified Sports was created to ensure that people with and without ID would have the opportunity to play together in competitive sports, thereby breaking down barriers that have historically kept these individuals isolated from one another (Siperstein \& Hardman, 2001).

Unified Sports includes a variety of indoor and outdoor sporting events from which to choose. Basketball, bowling, golf, softball, and volleyball are the common sports that provide a broad range of Unified Sports activities to meet most students' personal needs. For each sporting event, 8 weeks of training are required prior to participating in any official competitions (Malafronte \& Hall, 2005). Unified Sports participants have the opportunity to develop and improve sportspecific skills and experience new physical and mental challenges. Team members may improve their self-esteem, develop friendships, and gain an understanding of each other's capabilities through a spirit of equality and team unity (Roswal, 2007). Unfortunately, there are limited studies (Castagno, 2001; Siperstein \& Hardman, 2001; Norins-Bardon \& Brecklinghaus, 2005), which have been carried out to determine whether Unified Sports participation leads to achievement of goals and to assess the value and impact of the program.

Siperstein and Hardman (2001) investigated the attitudes of those involved in the Unified Sports Program. Ninety percent of the participants with disabilities indicated that they wished to continue their participation the following year, as they worked well with all the members on their team. Families involved in the study reported improvements in their students' physical abilities, self-esteem/selfconfidence, and relationships with peer athletes and peers at school. The researchers concluded that Unified Sports appears to have a positive effect on participants on multiple levels, and is a beneficial branch of the Special Olympics for families and students at the local level.

Castagno (2001) investigated the changes in self-esteem, basketball skills, and the behavioral intentions of male athletes with and without ID during a Unified basketball season. The post program questionnaire was used by coaches to rate their level of satisfaction with the Unified basketball season and to offer any concerns they might have about the program. It was reported that the positive changes in selfesteem, self confidence, and the desire to make new friends which were perceived by the coaches of this program lend further support to the claim that the Unified Sports Program provides benefits to all who participate. Coaches perceived an increase in self esteem for $67 \%$ of the SO athletes and $68 \%$ of the partners, as well as an increase in overall selfconfidence.

In 2005, Special Olympics Europe/ Eurasia developed a school-based pilot project that merged the Special Olympics school curriculum "SO Get Into It"® with Special Olympics Unified Football. The goals of this pilot project were to improve the sports skills, social skills, and self-esteem of students with and without ID. In addition, the project aimed to improve the understanding and acceptance of people with intellectual disabilities by students without disabilities. The findings of this evaluation suggest that this model of Unified Football has been successful in promoting social inclusion. Though separated 
by their educational settings, these students with and without ID have come together on the playing field to learn about sports and one another (Norins-Bardon \& Brecklinghaus, 2005).

In addition to previous studies (Castagno, 2001; Siperstein \& Hardman, 2001; NorinsBardon \& Brecklinghaus, 2005), the basis of present study comes from Sherrill's philosophy (Sherrill, 1985-1988) and Allport's contact theory (Allport, 1954). With regard to philosophy, Sherrill (1985) suggested that through interacting with one another, individual with and without disabilities discover dimensions of themselves and of the life that they did not know existed in sporting contexts. Individual differences are accepted, highlighted, and celebrated. According to Sherrill (1988), a major value of properly conducted physical education is to change negative feelings about the self by building success into movement experiences until such a time that the child becomes secure enough to react normally to occasional failures.

Allport (1958), the founder of contact theory, argued that increased contact (by itself) between different groups of individuals is not sufficient for acceptance. According to Allport, prejudice may be reduced by equal status contact between majority and minority groups in the pursuit of common goals. Many researchers have also used contact theory to explain what factors or variables related to contact quality influence formation of positive attitudes toward children with disabilities (Murata, Hodge, \& Little, 2000; Slininger et al., 2000; Tripp, French, \& Sherrill, 1995). In the study of Tripp et al. (1995), it was revealed that contact with the students with disabilities did not significantly affect attitudes of students without disabilities. Tripp et al. (1995) suggested that the large physical education class sizes in the inclusion classes may have limited the intensity of contact needed to cause significant changes in attitudes. On the other hand, Murata et al. (2000) found that contact could have a positive effect on attitudes. They noted several variables such as equal status, social interactions being encouraged by the general physical education (GPE) teacher, pleasant and rewarding contact contributed to the positive results. The key to these positive findings were that the GPE teacher and the teacher assistants facilitated social interactions, noncompetitive play, and positive interactions. Slininger et al. (2000) used a pretest-posttest randomized group design to determine the effects of structured contact on attitudes and intentions of students toward their peers who had a severe intellectual disability and used wheelchairs. Finding of this study showed that expected attitudes changes for the structured class setting did not occur after four weeks in cooperative games and rhythms. Reasons could have been such as large class sizes, and positive attitudes at pretests. When designing the present study, we considered previous studies' directions such as small class size, pleasant rewarding, contact and equal status which were also emphasized by Unified Sport Program.

With this context, our first hypothesis was that an individual without ID would learn about individual differences through participation in a Unified Football Program. Our second hypothesis was that individual with and without ID would improve more positive feelings about themselves through participation in a Unified Football Program. The purpose of the study was to compare the perceptions of athletes, partners, parents, and coaches regarding their commitment to the concept of Unified Sports, and their overall satisfaction with the Unified Sports Program at the beginning and the end of the program.

\section{METHOD}

\section{Participants}

At the beginning of the program, the boys with ID were sent to the Antalya Government Department of Consultancy and Research Centre to assess their intellectual disability. The Leither and WISC-R Intelligence Tests were applied according to their level of development. The Antalya Government Department of Consultancy and Research Centre did not provide the scores on the children's mental disability, but submitted descriptive data defining their levels as normal, mild, moderate, or severe. Participants with ID 
who were diagnosed with mild intellectual disability were involved in this study (Pitt, Roboz \& Plant, 1974). The participants with and without ID were prescreened by physicians for medical contraindications to exercise and for problems that would prevent them from football training. Participants were 46 boys with and without ID (23 with ID, age $=14.5 \pm 1.19, \quad 23$ without ID, age $=14.1$ \pm 0.89 ) between 12 and 15 years of age. They were attending a special education school, with mild intellectual disability, having no second handicap according to the criteria of Unified Sport. Partners were selected from a regular secondary school which was located in the same district. The researcher and school administrator made random selections among all students with the same age and gender by using computer. All parents of children participating in the study gave written informed consent, and the study was approved by the Research Ethics Committee, Akdeniz University.

\section{Materials}

\section{Special Olympics Unified Sports Questionnaire}

This questionnaire was used by parents, teachers and coaches to rate their level of satisfaction with Unified Sports and to offer any concerns they might have about the program. Also, coaches were asked to rate their perceptions of the impact of the program on their individual athletes across 15 dimensions (Special Olympics International, 1994; Castagno, 2001). No reliability or validity estimations have been calculated.

The Unified Sports Questionnaire included open-ended questions, close-ended questions, questions using the Likert scale, and questions involving ranking/rating of goals and priorities. Open-ended questions assessed participants' likes and dislikes regarding Unified Sports, as well as their specific experiences as an athlete, partner, family member, or coach. Questions for the athletes and partners focused on their relationships with other athletes and partners during sporting events, and in settings outside of Unified Sports. Several questions for athletes and partners addressed their selfperceptions in terms of the degree to which they felt their sports skills and self-confidence had improved. Questions specific to the partners addressed their assessment of their level of play in terms of competitiveness and their reactions to playing alongside athletes with ID. Questionnaires for family members and coaches focused on what they liked most and least about Unified Sports. Both family members and coaches were asked to indicate their goals and priorities for the athletes and partners. Parents were asked to judge their son's or daughter's improvements in a range of areas (such as physical abilities and relationships with others). Lastly, both family members and coaches were asked about specific issues regarding the operations of Unified Sports, specifically issues of partner dominance, modification of rules, communication with staff, problems with transportation, etc. (Siperstein \& Hardman, 2001).

The Unified Sports Questionnaire was translated into Turkish by three professional bilingual translators and translated back into English (back translation) by three other bilingual translators. After review, the translation committee agreed on a version of the Unified Sports Questionnaire that best reflected the linguistic and conceptual content of the original questionnaire.

\section{Procedure}

\section{Assessments}

Assessments were made in two phases of the study, at the beginning and end of the Unified Football Program on athletes and partners. The questionnaire forms were administered to athletes and partners as a pretest in the second week of the training and post test just after the tournaments in the eleventh week of the study. Because the items of the questionnaire pertained participant perceptions about the program, the participants first needed some experience with the program. For that reason, the second week of training was selected for the pretest. The questionnaires were administered to athletes, partners and parents in separate groups. The questionnaire forms were administered to parents and coaches only after the program. Because of 
some parents' and athletes' insufficiency in reading and writing skills, the questionnaires were administered to them via interview by the researcher. Researcher just read the items in questionnaire and wrote the participant response to the questionnaire form. This protocol was used in the same way and by the same researcher for all measurements of participants.

\section{Training groups and season}

The groups were trained by a total of 8 coaches and one head coach, 2 coaches in every group for 8 weeks. To facilitate the training, athletes were divided into four heterogeneous teams, with equal numbers of the athletes and partners. Training season was 8 weeks, $1.5 \mathrm{hr}$ per session, three times per week. The Football Coaching Guide (www.specialolympics.org/football.aspx) was referred to during the experimental training, including skills and rules of football, sportsmanship, and some team tactics. Sessions were started with warm-up exercises. They involved exercises without the ball, including stretching, coordination, strengthening and running exercises with and without the ball. These exercises and drills took 20 minutes for the first five sessions. The time reserved for warming up gradually decreased to ten minutes due to improvements in the skills of the subjects. After warming up, the subjects engaged in football drills. The training program included techniques with and without the ball, dribbling, stopping, blocking, and dodging techniques, team tactics and match tactics. A tournament was held at the end of 8 weeks, and the parents joined as spectators. At the end of the tournament, all teams were given a first, second, third or fourth place medal.

\section{Data Analysis}

Data from the Unified Sports Questionnaire were analyzed using a nonparametric test. The effects of the Unified Football Program were examined by using McNemar's test on athletes' and partners' pre- and post-program responses. Athletes' and partners' parents post program perceptions were examined by using Chi-square test. For analyzing simple $2 \times 2$ contingency tables, when the assumptions for the Chi-squared test were not met, Fisher's Exact test was used. A p-value $p<0.05$ was considered statistically significant.

\section{RESULTS}

In accordance with the aim of the study to examine the changes occurring in SO athletes' and partners' perceptions about the Unified Sports Program - pre- and postmeasurement responses of the participants were compared. In addition to pre- and postmeasurement comparison, the post-program perception of parents and coaches were examined.

\section{Perception of Partners about the Unified Football Program}

The before- and after-program responses of the partners are presented in Table 1. There was a significant difference between the before and after program responses of partners in the item "How much do you like training or practices?" $\left[X^{2}(1, N=23)=8.10, \mathrm{p}=.<05\right]$. At the beginning of the program, partners enjoyed the training or practice in Unified Sports "a lot". In the post program measurement, there was a decrease in the partners' enjoyment of training or practice. The second significant change seen after the Unified Sports Program in partners' perception was in the "Level of getting along with the other school friends" $\left[X^{2}(1, N=23)=5.82, \mathrm{p}<.05\right]$. When asked if they get along with the other school friends in this program, most of the partners reported "yes" at the beginning of the program, while at the end there was a decrease of "yes" responses. When asked, "Do you have a better understanding of individuals with intellectual disabilities?" there were no statistically significant differences before and after the program $\left[X^{2}(1, N=23)=.50, \mathrm{p}>.05\right]$. 
Table 1

Partners' response to Unified Sport Questionnaire before and after program measurements

\begin{tabular}{|c|c|c|c|c|c|c|}
\hline & \multicolumn{2}{|c|}{$\begin{array}{c}\text { Before } \\
\text { Program }\end{array}$} & & \multicolumn{2}{|c|}{$\begin{array}{c}\text { After } \\
\text { Program } \\
\end{array}$} \\
\hline & & $\mathrm{N}$ & $\%$ & & $\mathrm{~N}$ & $\%$ \\
\hline \multirow[t]{2}{*}{ How much do you like training or practices? } & Not at all & 2 & 8.7 & \multirow{2}{*}{$X^{2}(1, N=23)=8.10, \mathrm{p}=.<05$} & 12 & 52.2 \\
\hline & A lot & 21 & 91.3 & & 11 & 47.8 \\
\hline \multirow{2}{*}{$\begin{array}{l}\text { Do you get along with the other school } \\
\text { friends in this program? }\end{array}$} & No & 5 & 21.7 & \multirow{2}{*}{$X^{2}(1, N=23)=5.82, \mathrm{p}<.05$} & 14 & 60.1 \\
\hline & Yes & 18 & 78.3 & & 9 & 39.1 \\
\hline \multirow{2}{*}{$\begin{array}{l}\text { As a result of your participation in Unified } \\
\text { Sports, do you have a better understanding of } \\
\text { individuals with intellectual disability? }\end{array}$} & A little better & 11 & 47.8 & \multirow[b]{2}{*}{$X^{2}(1, N=23)=.50, \mathrm{p}>.05$} & 13 & 56.5 \\
\hline & A lot better & 12 & 52.2 & & 10 & 43.5 \\
\hline
\end{tabular}

Perception of Special Olympic Athletes about the Unified Football Program

During the Unified Football Program there was a significant change between before- and after-program measurements only in the item "Would you recommend Unified Sports to a friend?" $\left[X^{2}(1, N=23)=6.13\right.$, p>.05]. Athletes' recommendation of Unified Sports to a friend was higher at the end of the program compared to beginning of the program.
Additionally, when asked if the athletes see any of the other athletes from their team when they are not playing, all the athletes indicated that they saw teammates only in the school environment. They did not have social contact with their teammates at home or in the community (Table 2). On the other hand, while all the partners reported that they had an interaction with teammates in school and the community, $87 \%$ of partners had interactions at home.

\section{Table 2}

Athletes' and partners' response to the item "Do you see any of the athletes from your team, when you are not playing unified football?"

\begin{tabular}{|l|l|l|l|l|l|l|l|l|l|l|}
\hline \multicolumn{2}{|c|}{} & \multicolumn{4}{|c|}{ Before Program } & \multicolumn{4}{c|}{ After Program } \\
\cline { 3 - 11 } \multicolumn{2}{|c|}{} & Athlete & Partner & \multicolumn{2}{|c|}{ Athlete } & \multicolumn{2}{l|}{ Partner } \\
\cline { 3 - 11 } & $\mathrm{N}$ & $\%$ & $\mathrm{~N}$ & $\%$ & $\mathrm{~N}$ & $\%$ & $\mathrm{~N}$ & $\%$ \\
\hline \multirow{3}{*}{ School } & Seeing & 23 & 100 & 23 & 100 & 23 & 100 & 23 & 100 \\
\cline { 2 - 11 } & Not seeing & 0 & 0 & 0 & 0 & 0 & 0 & 0 & 0 \\
\hline \multirow{3}{*}{ Home } & Seeing & 0 & & 20 & 87 & 0 & 0 & 20 & 87 \\
\cline { 2 - 11 } & Not seeing & 23 & 100 & 3 & 13.0 & 23 & 100 & 3 & 13.0 \\
\hline \multirow{3}{*}{ Community } & Seeing & 0 & 0 & 23 & 100 & 0 & 0 & 23 & 100 \\
\cline { 2 - 10 } & Not seeing & 23 & 100 & 0 & 0 & 23 & 100 & 0 & 0 \\
\hline
\end{tabular}


Parents' Perceptions about the Unified Sports Program

Both athletes' and partners' parents were asked at the end of the program about their perception related to the effects of the Unified Football Program on their children's development (Figure $1 \&$ Figure 2). When the perceptions' of parents in post program measurement were compared, there were no significant differences in perception of improvement in sport-specific physical abilities $\left[X^{2}(1, N=23)=1.46, \mathrm{p}>.05\right]$, in selfesteem/self-confidence $\left[X^{2}(1, N=23)=1.08\right.$, $\mathrm{p}>.05]$, in health $\left[X^{2}(1, N=23)=.10, \mathrm{p}>.05\right]$, in adaptive behavior $\left[X^{2}(1, N=23)=.09\right.$, $\mathrm{p}>.05]$, in fellow relations $\left[X^{2}(1, N=23)=\right.$ $1.24, \mathrm{p}>.05]$, in partner relations $\left[X^{2}(1, N=\right.$ $23)=3.45, \mathrm{p}>.05]$, in peer relations $\left[X^{2}(1, N\right.$ $=23)=0.10, \mathrm{p}>.05]$, and in family members relations $\left[X^{2}(1, N=23)=.10, \mathrm{p}>.05\right]$ of their children between athletes' and partners' parents. Both parents reported great improvement of their children in all dimensions. The highest improvement reported by parents was in relationships with fellow athletes.

Figure 1. Perception of athletes' parents on athlete improvement at the end of the program

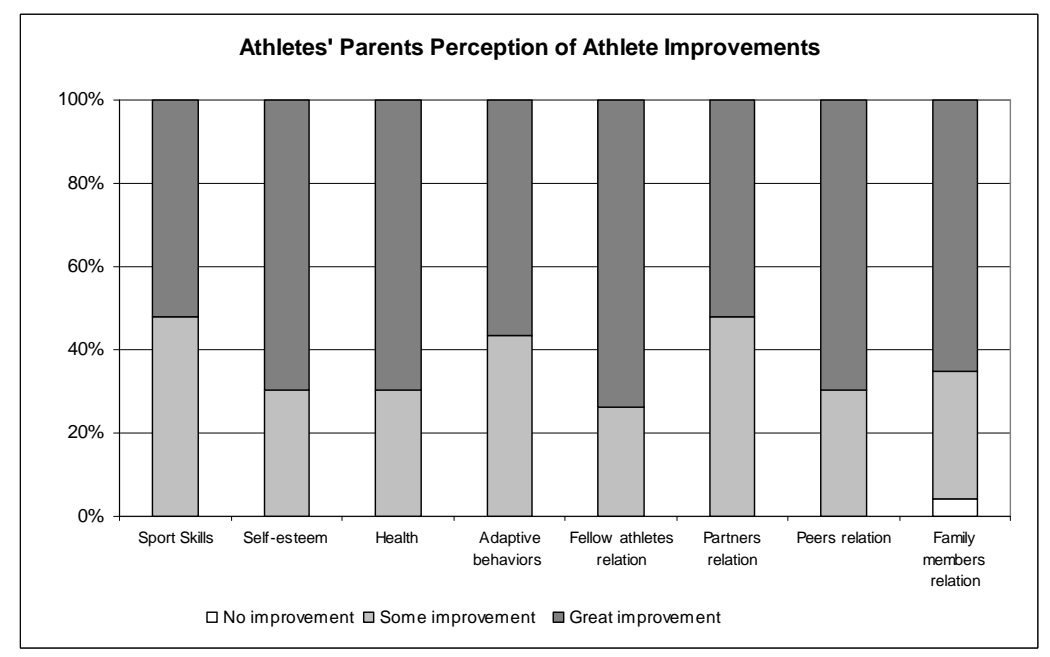

Figure 2. Perception of partners' parents perception on athlete improvement at the end of the program.

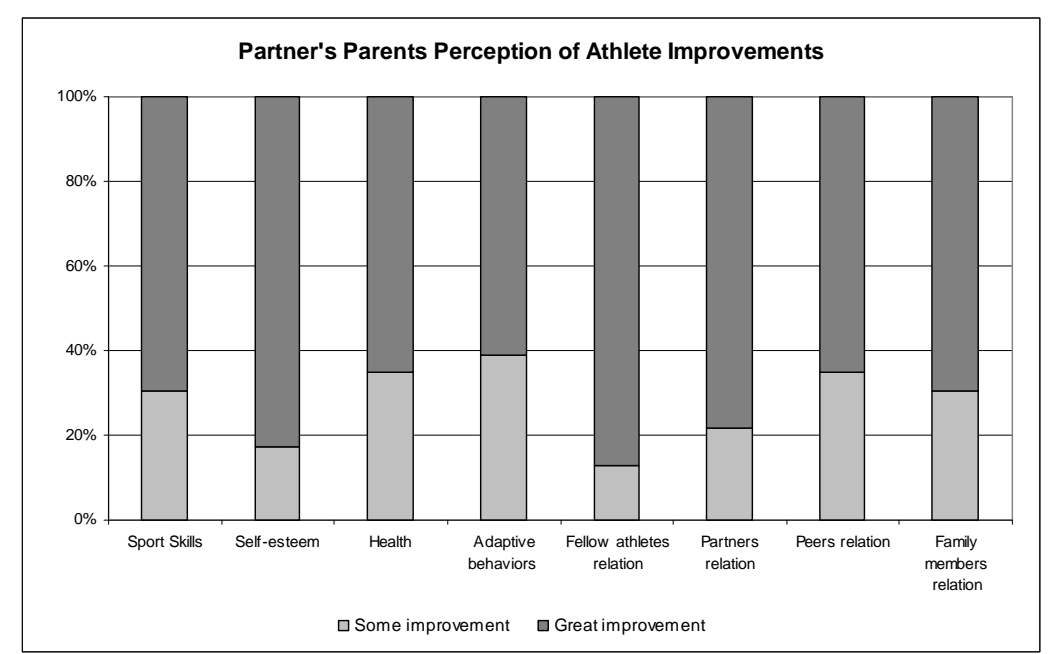


Coaches' Perceptions about the Unified Sports Program

The Unified Sports Coaches Questionnaire was administered to 8 coaches who took part in the Unified Football Program. All of the coaches were students in the department of physical education and sports at Akdeniz University, and reported that they had never taken part in a Unified Sports program and that they were not related to any athlete or partner in the program. In regard to their training and experience level, $50 \%$ of coaches had experience in traditional SO, $87.5 \%$ worked as a coach on other teams, and $75 \%$ preferred coaching in Unified Sports.

The item related to the decision making role of coaches showed that, all of the coaches believed in the necessity of rule modification during the program. While $62.5 \%$ of coaches reported that the reason for rule modification was "to accommodate an athlete's or partner's skills", $25 \%$ of coaches reported that rule modification was to "deal with partner dominance". Coaches were also asked to identify several perceived problem areas relative to their local Unified Sports program. The most common problems identified were a) attrition of athletes $(72.5 \%)$, (b) domination of partners $(50 \%)$, (c) attrition of partners $(37.5 \%)$, and (d) matching age and ability of partners and athletes (37.5\%).

\section{DISCUSSION}

The results of the present study contribute to our understanding of the changes about the perception of athletes, partners, parents, and coaches during the Unified Football Program. We posited two main hypotheses: (a) Partners would learn about individual differences through participation in a Unified Football Program, and (b) partners and athletes would improve more positive feelings about themselves through participation in a Unified Football Program.

Our first hypothesis was not supported because the results from the Unified Sports Partner Questionnaire revealed that after the eight week football program there were decreases in partners' enjoyment of practice and their level of getting along with the other school friends. Partners also did not show expected changes in terms of having a better understanding of individuals with ID at the end of Unified Football Program.

However, none of the partners agreed with the statement "I can get on well with nobody" both at the beginning and at the end of the program. At the beginning of the program, information about intellectual disabilities and characteristics of children with ID was given to the partners by showing a film about children with intellectual disabilities who attend the Special Olympics Games. Their need to have a friend without a disability and to be included in society was emphasized. Partners' initial level of getting along with athletes may be due to the effects of this information given before the program.

Previous studies (Castagno, 2001; Siperstein \& Hardman, 2001; Norins-Bardon \& Brecklinghaus, 2005), give us no clue about the change in partners' enjoyment of practice and their level of getting along with the other school friends because they were not designed to compare pre- and post-participation results.

It is possible to use the coaches' postprogram perceptions in this research to explain the decrease in partners' level of getting along with athletes after the program. According to the results of the Unified Sports Coaches Questionnaire, coaches reported attrition for both athletes and partners. This attrition might be a reason for the decrease in the partners' enjoyment of training. During the Unified Football Program all the coaches believed that it was necessary to make rule modifications. The most commonly reported reason for rule modification was "to accommodate an athlete's or partner's skills" followed by "to deal with partner dominance". In the study by Siperstein and Hardman (2001), while 58 percent of the coaches stated that they believed rule modification was essential, 35 percent stated that rule modification was related to the partners' dominance. Unlike the findings in our study, $77 \%$ of the coaches stated that the partners and the athletes contributed to the team equally. However, in the present study $75 \%$ of the coaches stated that the partners contributed more than the athletes. In our 
study, although equal ability levels were aimed for when constituting the groups, the findings can be considered as a clue to some difference in the ability levels between the athletes and the partners. Considering that athletes had an intellectual disability, the difference in the ability levels seems natural. Probably if seniority of athletes was provided, it might also provide more equality in ability levels.

Non significant changes in terms of having a better understanding of individual with ID at the end of Unified Football Program in partners may be result from their better understanding of individual with ID at the beginning of Unified Football Program. As explained before, the Unified Sports Questionnaire was applied in the second week of the study. During this period athletes and partners participated five training sessions.

Results from the Unified Sports Athlete Questionnaire showed that after the football program, there was an increase in athletes' recommendation of Unified Sports to their friends. These results suggest that during the football program athletes benefited from interaction with partners and developed positive feelings towards partners. Athletes indicated that they saw their friends only at school. They did not have any opportunity to be in contact with their friends or partners outside the school. However, partners had an opportunity to be in contact with their friends in school, society and at home. This Unified Football Program enabled the athletes to be in contact with both their friends and partners via sports. The athletes' recommendation of Unified Sports to their friends may be the result of this enjoyable social environment. Owing to meeting their sport equipment for playing (cleats and sportswear), having friends, being a part of the group, providing their transportation with bus and receiving a medal in podium after tournament may have contributed this enjoyment.

This is consistent with the stated aims of Unified Sports: to break down the social barriers between individuals with and without ID (Siperstein \& Hardman, 2001). In this aspect, the findings seem to be consistent with those obtained in a study conducted by Fenning et al. (2000). In that study perceived learning outcomes pertained to increased understanding of individual differences and sportsmanship. References to understanding differences were the most frequent responses given when participants were asked what was learned at the one-day basketball tournament.

Our second hypothesis was supported because athletes' parents stated that, thanks to the program, their children gained a wider social life, participated in sports, had closer relationships within the society, developed their skills in communication and sports, became more self-confident, well-adjusted and happier. The parents of both athletes and partners stated that their children improved in terms of sports skills, communication, selfconfidence, health and adjustment, which can be considered as the positive contribution of the program. This supports the anecdotal acknowledgment from parents, coaches, and athletes that the Unified Sports Program promotes high self-esteem in all participants (Siperstein \& Hardman, 2001; Castagno, 2001). In the study of Siperstein and Hardman (2001), families perceived the most improvement in physical abilities, selfesteem/self-confidence, and relationship with fellow athletes. Family members also saw significant improvements in the areas of adaptive behaviors, relationships with peers at school or work, relationships with parents and siblings, and relationships with other adults.

In the present study, the coaches stated that their primary goal was to develop athletes' selfrespect and self-confidence and their secondary goal was to improve their sports skills. In addition, they stated that in the competitions they focused firstly on team spirit, secondly on ethical behavior in sports and team success, and thirdly on entertainment. In contrast, Siperstein and Hardman (2001) stated that the coaches aimed primarily at entertainment, teamwork and ethical behavior in sports.

The partners' parents preferred Unified Sports more than traditional sports at the end of the program, and this might lead us to consider the positive effects of the Unified Sports program. While determining the subject groups, the biggest concerns of the partners' 
parents was that their children would be hurt, and that they would model negative behaviors, which resulted in difficulties in the participation of the partners in the study.

Similarly, in the study of Siperstein and Hardman (2001), 93\% of the athletes' parents stated that they were satisfied with the Unified Sports experience. Also, 98\% of the parents stated that they were going to recommend the program to other parents, and $91 \%$ of the parents pointed out that coaches in the program are qualified enough to work with athletes with ID.

Athletes and partners had positive feelings about themselves both at the beginning and at the end of the program so, there was no significant change. The main reason is, the item related to feelings about themselves was asked to the athletes and partners in the second week program.

According to the results of this study, increasing the popularity of Unified Sports in other sports branches would enable children with ID to integrate into society and increase the social awareness of individual without disabilities.

\section{CONCLUSION}

The results from the evaluation of the unified football program revealed that partners had a better understanding of individuals with ID as a result of their participation, although there were decreases in partners' enjoyment of practice and their level of getting along with the other school friends at the end of the program.

Unified Football Program enabled the athletes to be in contact with both their friends and partners via sports. Considering that athletes do not have any opportunity to be in contact with their peers outside the school, it has been thought that Unified Football Program constituted better social environment which met their psychosocial needs. Anecdotal acknowledgments from parents supported the positive contributions of Unified Football Program on the athletes. Athletes' parents stated that thanks to the program, their children gained a wider social life, participated in sports, had closer relationships within the society, developed their skills in communication and sports, and became more self-confident, well-adjusted and happier.

\section{REFERENCES}

Allport, G. W. (1954). The nature of prejudice. Reading, MA: Addison-Wesley.

American Association on Intellectual and Developmental Disabilities (AAIDD). (2009). Definitions of intellectual disability. Retrieved April 28, 2009, from http://www.aamr.org/content_100.cfm?navID $=21$

Arbogast, G., \& Lavay, B. (1986). Combining students with different ability levels in games and sport. Physical Educator, 44, 255-260.

Block, M. (2000). A teachers guide to including students with disabilities in general physical education . (2[supnd] ed.) Baltimore, MD: Paul H. Brookes.

Castagno, K. S. (2001). Special Olympics Unified Sports: Changes in male athletes during a basketball season. Adapted Physical Activity Quarterly, 18, 193-208.

Fenning, P., Parraga, M., Bhojwani, V., Meyer, A., Molitor, M., Malloy, M., Labiak, L., Taube, I. \& Mulcrone F. J. (2000). Evaluation of an integrated disability basketball events for adolescents: Sportmanship and learning. Adapted Physical Activity Quarterly, 17, 237-252.

Heikinaro-Johansson, P., \& Vogler, W. (1996). Physical education including individuals with disabilities in school settings. Sport Science Review, 5, 12-25.

Mahon, M. J., Mactavish, J., Bockstael, E., O’Dell, I. \& Siegenthaler, K. L. (2000). Social integration, leisure, and individuals with intellectual disability. Parks \& Recreation, 35(4), 25-33.

Malafronte, A. \& Hall, G. (2005). Unified sports coaches handbook: Connecticut interscholastic athletic conference; Special Olympics Connecticut. Washington DC: Special Olympics. Retrieved March 3, 2006, from www.casciac.org/pdfs/Unified_Sports_Hand book.pdf

Norins-Bardon, J., \& Brecklinghaus, S. (2005). Evaluation of the Special Olympics Europe 
/Eurasia Unified Football Pilot-Project: Findings from Austria, Poland, Romania, Serbia and Slovakia. Retrieved August 13, 2008, from http://info.specialolympics.org/ NR/rdonlyres/ecuoyiji7e4vm7hbh62qf2chom xtumqwrei5h4o3iapwslkrenhhe77mqxpnnzm ov4nzmnvxbzedekathh2tob2boea/SOEE+Uni fied+Football.pdf

Pitt, D., Roboz, P., \& Plant, E. (1974). The classification of mental deficiency. Journal of Intellectual \& Developmental Disability, 3, 70-76.

Roswal, M. G. (2007). Special Olympics unified sports: Providing a transition to mainstream sports. Sobama Journal, 12(1), Supplement, 13-15.

Siperstein, G. N., Harada, C. M., Parker, R. C., Hardman, M. L., \& McGuire, J. (2008). Changing attitudes changing the world $A$ comprehensive national study of Special Olympics programs in the United States. Retrieved April 24, 2009, from www.specialolympics.org
Siperstein, G. N., \& Hardman, M. L. (2001). National evaluation of the Special Olympics Unified Sports Program, Appendix B; Athlete Questionnaire, Family

Member

Questionnaire, Partner Questionnaire, Coaches Questionnaire, Final Report. Retrieved March 9, 2005, from www.specialolympics.org

Special Olympics International, Incorporated. (1994). Special Olympics Unified Sports Questionnaire. Washington, DC: Joseph P. Kennedy Jr. Foundation.

Wehmeyer, M., \& Schwartz, M. (1998). The relationship between self-determination and quality of life for adults with mental retardation. Education and Training in Mental Retardation and Developmental Disabilities, 33(1), 3-12.

Corresponding author's e-mail address: ozerd@comu.edu.tr

This project was supported by the Akdeniz University Research Foundation, project number: 2004.01.0122.001.

\section{EVALUATION DES UNIFIED FUSSBALL PROGRAMMS DURCH SPECIAL OLYMPICS ATHLETEN, PARTNER, ELTERN, UND TRAINER}

(Resümee)

Die Absicht dieser Studie war ein Vergleich der Wahrnehmungen von Athleten, Partnern, Eltern und Trainern hinsichtlich ihres Engagement für das Konzept von Unified Sports sowie deren Gesamtzufriedenheit mit dem achtwöchigen Unified Fußball Programm zu Beginn und am Ende des Programms. Die Teilnehmer waren 46 Jungen mit und ohne intellektuelle Beeinträchtigung (IB) (23 mit IB, Durchschnittsalter $=14.5 \pm 1.19$ Jahre, 23 ohne IB, Durchschnittsalter $=14.1 \pm 0.89$ Jahre). Die Unified Sport Fragebögen wurden den Athleten, Partnern, Eltern und Trainern als Pre-Test in der zweiten Trainingswoche ausgefolgt, ein Post-Test fand unmittelbar nach den Wettkämpfen statt. In den nach dem Programm erhobenen Antworten der Partner konnte ein signifikanter Abfall in der Trainingsfreudigkeit ( $\mathrm{p}<.05, \mathrm{McNemar}$ 's Test) und in der Wahrnehmung des Ausmaßes, sich mit Schulfreunden gut zu verstehen ( $\mathrm{p}<.05, \mathrm{McNemar}$ 's Test), festgestellt werden. Bei den Athleten gab es nur in der Weiterempfehlung von Unified Sports an einen Freund einen signifikanten Anstieg ( $\mathrm{p}<.05, \mathrm{McNemar}$ 's Test). Die Eltern von Athleten und Partnern bemerkten Verbesserungen in Fähigkeiten, Verhalten und Beziehungen ihrer Kinder. Alle Trainer glaubten an die Notwendigkeit von Regeländerungen während des Programms. Gemäß den Ergebnissen dieser Studie ermöglicht Unified Sports die Integration von Kindern mit intellektueller Beeinträchtigung in die Gesellschaft und verbessert das soziale Bewusstsein ihrer Peers ohne Behinderung.

SCHLÜSSELWÖRTER: Special Olympics, Unified Sports Programm, intellektuelle Behinderung, Fußball. 


\section{EVALUATION D'UN PROGRAMME DE FOOTBALL UNIFIE PAR DES ATHLETES SPECIAL OLYMPICS, LEURS PARTENAIRES, PARENTS, ENTRAINEURS}

(Résumé)

Le but de cette étude était de comparer les perceptions des athlètes, les partenaires, les parents et les entraîneurs quant à leur attachement au concept de Unified Sports, et de mesurer leur satisfaction globale au début et à la fin d'un programme de 8 semaines de football unifié Les participants étaient 46 garçons avec et sans déficience intellectuelle (DI) (23 avec DI, âge moyen $=$ 14,5 $\pm 1,19$ ans, 23 valides, âge moyen $=14,1 \pm 0,89$ ans). Le questionnaire "Unified Sports" a été administré aux athlètes, aux partenaires, aux entraîneurs et aux parents comme pré-test au cours de la deuxième semaine du programme et comme post test, juste après les tournois. Il ya eu diminution sensible dans les réponses de fin de programme des partenaires sur la satisfaction liée à l'entraînement ( $\mathrm{p}<.05$, test de McNemar) et de la perception du niveau d'entente avec les autres camarades de classe ( $\mathrm{p}<.05$, test de McNemar). Chez les athlètes, il ya eu une augmentation significative uniquement dans la recommandation de Unified Sports à un ami (p <.05, test de McNemar). Les parents des athlètes et des partenaires ont fait état d'améliorations des compétences, des comportements et des relations de leurs enfants. Tous les entraîneurs ont insisté sur la nécessité de modifier les règles au cours du programme. Selon les résultats de cette étude, Unified Sports permettrait d'intégrer les enfants ayant une déficience intellectuelle dans la société et d'accroître la prise de conscience sociale de leurs pairs non handicapés.

MOTS CLEFS : Special Olympics, programme Unified Sports, déficience intellectuelle, football. 